Katarzyna Ożańska-Ponikwia

University of Bielsko-Biala, Poland

\section{Angélica Carlet}

Universitat International de Catalunya, Spain

\section{Maria Pujol Valls}

Universitat International de Catalunya, Spain
iD https://orcid.org/0000-0003-4896-0521

iD https://orcid.org/0000-0001-8411-4731

iD https://orcid.org/0000-0001-6314-4675

\title{
L2 Gain or L2 Pain? A Comparative Case Study of the Target Language Development among Erasmus+ Mobility Students and At-Home Students*
}

\begin{abstract}
The Erasmus+ exchange program has become very popular, with the numbers of student sojourners growing each year. However, it has previously been observed that not all students benefit equally from the study abroad (SA) experience (cf. Kinginger, 2008, 2009; Marijuan \& Sanz, 2018; Mitchell, Tracy-Ventura \& McManus, 2017; Regan, Howard \& Lemée, 2009). Consequently, the main aim of the present study was to investigate various factors that might contribute to the development of the target language among two small groups of students, one of which self-selected themselves to undertake their language teaching practicum abroad, as a part of the Erasmus + mobility program $(n=6)$, and the other at local schools in the country of their residence $(n=5)$. Both groups were examined prior their departure and after their return with a battery of tests that included: Oxford Placement test, Self-reported proficiency questionnaire, Oral proficiency test based on Cambridge Advanced exam, Language Engagement Questionnaire, Multicultural Personality Questionnaire (MPQ), Big Five Personality Questionnaire, and Trait Emotional Intelligence Questionnaire (TEIQue). Our findings demonstrated that the majority of the Erasmus + mobility program students examined in this study showed some greater linguistic progress in grammar and speaking in comparison to the at-home students. However, there were two cases that failed to progress after the stay abroad experience. Further analyses and interviews showed that some other factors such as attitudes, language engagement, and

\footnotetext{
* The data collection and analyses were possible thanks to a Short Term Scientific Mission (STSM) grant awarded by COST Action CA15130 Study Abroad in the European Perspective.
} 
satisfaction with the Erasmus experience might in fact influence and shape target language development while abroad. At the same time, it could be speculated that, in the case of researched informants, their progress in grammar and speaking could be assigned mostly to the amount and quality of the language input outside of the classroom setting.

Keywords: L2 gains, stay abroad, Erasmus + mobility, personality, attitudes, satisfaction

\section{L2 Gains in the Study Abroad Context}

The general assumption that study abroad (SA) leads to solid linguistic gains continues to generate vigorous debate (DeKeyser, 2010; Grey, Cox, Serafini, \& Sanz, 2015). Research on linguistic development among sojourners has continued to note considerable variability in learning outcomes, and some researchers have sought to explain this variability with reference to individual differences such as initial L2 proficiency level, working memory and other cognitive factors, though without clear success (Mitchell, Tracy-Ventura, \& McManus, 2017, p. 8). Consequently, a commonly held assumption that a study abroad setting is the ideal environment in which to learn a second language was questioned. Bryfonski and Mackey (2018) noted that even though sojourners might have wider access to interactions with native speakers than they do in their home contexts, the link between language gains and the amount and frequency of that contact while abroad has not yet been firmly established (e.g., Freed, Segalowitz, \& Dewey, 2004, p. 374). It was also observed that the immersion experience does not always lead to language development and growth (Cubillos, Chieffo, \& Fan, 2008; Freed, 1995; Sanz, 2014; Segalowitz \& Freed, 2004), highlighting the fact that the process is more complex, dynamic, and nuanced. As Isabelli-García (2006) rightly stated:

studies that examine learners' attitude, motivation and behaviour in the host environment and link these factors directly to linguistic development can show that learners may not magically become fluent speakers simply by being surrounded by the target language. (Isabelli-García, 2006, p. 231)

Gardner (2012) noted that language is a defining characteristic of an individual who is involved in thoughts, self-communication, social interaction, and perception of the world. Language is an important part of one's identity, and the extent to which one can incorporate another language successfully is related to a variety of attitudinal variables that are influenced by the cultural milieu in which language learning takes place (Gardner \& Lalonde, 1985, p. 16). Pavlenko (2002, pp. 280-281) noted that "attitudes, motivation or language 
learning beliefs have clear social origins and are shaped and reshaped by the contexts in which the learners find themselves." What is more, they are never static as they depend on the interplay of many social, political, and linguistic circumstances (Pavlenko, 2005). Thus, it could be stated that foreign language learning (FLL) is part of the mental and emotional development of learners taking place in the multidimensional context of a society (Shabitha \& Mekala, 2013). Consequently, since the FLL process is dynamic and depends on various social, psychological, and linguistic factors, it could be postulated that the interplay of the above-mentioned variables might explain the wide variation in learners' success in acquiring and using a foreign language in a study aboard context. Therefore, this investigation aims to examine how different psychological (personality traits, emotional intelligence) and socio-psychological factors (attitudes, language engagement, satisfaction) are related to the development of the L2 grammar and oral communication skills during a short stay abroad period.

\section{Literature Review}

As noted by Hessel (2017), study abroad research has shown that the linguistic gains made by study abroad participants are often subtle and subject to substantial individual differences (Collentine, 2009; Freed, 1995; Kinginger, 2015; Sanz, 2014). As a consequence, there has been considerable research interest in identifying factors that can account for differential linguistic progress during study abroad to understand why some students make substantially greater gains than others. Baker-Smemoe et al. (2014) addressed a number of variables potentially related to L2 gain while abroad among more than 100 native English speakers participating in study abroad in Mexico, Spain, France, Egypt, Russia, and China. Informants' language gains were correlated with several predictors such as personality, social networks (size, dispersion, density, etc.), intercultural sensitivity, amount of second language use, gender, and age. The results demonstrated that pre-program competence variables (pre-program proficiency and intercultural sensitivity) and social/contextual variables (social network development) were greater predictors of language gains than were learner attribute variables (age, gender, or personality). In fact, results suggested that the development of social networks as well as the pre-departure level of cultural sensitivity were the variables that predicted most of the variance between gainers and non-gainers in the researched sample. Previous studies have already shown that developing social networks with native speakers while abroad via volunteer work, part-time employment, club membership, etc. can facilitate 
language acquisition (Isabelli-García, 2006; Whitworth, 2006). Isabelli-García (2006, p. 232), in a small-scale case study exploring how differences in motivation and attitude can affect L2 oral communication skills development, provided evidence of a four-way connection between SLA during the SA experience, motivation, intercultural adjustment and significant target language interaction with native speakers. These factors, according to the author, might explain the variation among individual learner's progress while abroad and illustrate:

the complex relationship between motivation, acculturation and the development of social networks that ultimately provide opportunities for exposure to the target language and extended interactions that might be the driving force behind language acquisition in the SA context. (Isabelli-García, 2006, p. 257)

Some other research studies suggested that cultural adjustment is, in fact, a very important factor that might influence both the development of the target language while abroad, as well as satisfaction with the SA experience. Basow and Gaugler (2017) reported that intercultural adjustment over the course of the study abroad semester was best predicted by a combination of individual and social factors. In particular, those who had less difficulty with cultural adjustment had stronger language skills initially, as well as higher levels of social interactions with locals during their sojourn. A higher level of social interactions, in turn, mediated the effects of higher levels of open-mindedness and more positive home-stay experiences. In some other studies (Harrison \& Voelker, 2008; Savicki et al., 2004) personality and emotional intelligence traits were also reported to influence intercultural adjustment. Savicki et al. (2004) investigated contrasts, changes, and correlates among study abroad students and found that clusters of personality traits (e.g., anxiety, extraversion, openness, and agreeableness) and coping strategies (e.g., active, planning, denial, and behavioural disengagement) related to intercultural adjustment. Similarly, Harrison and Voelker (2008) investigated the cross-cultural adjustment of study abroad students. The results of their study indicated that three sub-dimensions of EI were strongly related to a general adjustment to a host culture. Individuals with higher self-emotional appraisal, higher others' emotional appraisal and higher use of emotion exhibited stronger general adjustment than those who scored lower in these dimensions. When it comes to the role of personality dimensions and their relation to the amount of target language use and self-perceived progress in speaking, a very interesting study by Arvidsson et al. (2018) showed that an increase in cultural empathy correlated with both self-perceived progress in speaking and the amount of target language use. At the same time, an increase in open-mindedness was reported to correlate with the amount of target language use. The authors concluded that the mentioned personality traits are 
not only important for the ability to understand and interpret other cultures, but it is also possible that creating social bonds with the target language community reinforces those personality dimensions (Arvidsson et al., 2018, p. 158). Therefore, it could be speculated that even though personality was not always directly linked to the SA students' L2 gains, it could have a direct influence on socialization in the host culture and frequency of L2 use in the immersive context, as well as development of social networks. Consequently, it could be suggested that its influence on L2 gains while abroad might be indirect.

Along the same lines, studies focusing on the immigrant setting also found personality and emotional intelligence to play an important role in explaining cross-cultural adjustment and expatriate employee success (Gabel et al., 2005; Huang, Chi \& Lawler, 2005; Jassawalla, Truglia, \& Garvey, 2004) but also L2 proficiency and frequency of L2 use (Ożańska-Ponikwia, 2015; OżańskaPonikwia \& Dewaele, 2012). Ożańska-Ponikwia (2015) reported that immersion in the L2 culture influenced self-perceived L2 proficiency and the degree of L2 use among Polish immigrants in the UK and Ireland. It was noted that the longer the participants in the study were immersed in the foreign culture, the more frequently they reported using L2 on an everyday basis. This could be explained by engagement in social interactions and building up new social networks in the L2, which, on the other hand, could be linked to higher and lower order personality traits (Ożańska-Ponikwia, 2013). Informants in her study also noticed that only by immersion and socialization in the L2 culture were they able to understand social, linguistic, and cultural aspects of L2 communication patterns, which influenced their self-perceptions as far as the degree and frequency of L2 use was concerned (Ożańska-Ponikwia, 2015). When it comes to personality traits and L2 use in the immigrant context, some previous studies (Ożańska-Ponikwia, 2013; Ożańska-Ponikwia \& Dewaele, 2012) confirmed that an immigrant's personality profile was significantly linked to L2 use and self-perceived proficiency in the L2, with agreeableness, openness and the EI trait of empathy influencing self-perceived L2 proficiency, and self-esteem, stress management, adaptability, wellbeing and the global trait of EI being related to L2 use. It was also suggested that openness and self-esteem are the personality traits that best predict the use and development of English L2 by Polish immigrants living in the UK or Ireland (Ożańska-Ponikwia \& Dewaele, 2012). Consequently, it could be speculated that personality characteristics that aid both adaptation, as well as intercultural communication, could also be considered important factors affecting L2 gains while abroad.

When it comes to the SA outcomes, Dewaele (2009, p. 636) noted that research on immersion education and study abroad showed that increased contact with L2 typically boosts the acquisition of different areas of L2, including sociolinguistic competence (Mougeon, Rehner, \& Nadasdi, 2004; Regan, 2005), socio-pragmatic competence (Kinginger, 2004), and grammatical competence 
(Howard, 2005; Howard \& Schwieter, 2018; Nadasdi, Mougeon, \& Rehner, 2003). However, it needs to be remembered that when it comes to sojourners' grammatical and lexical development, reported findings are inconclusive. There were noted both some positive effects on grammatical and lexical development during SA (e.g., Grey et al., 2015; Faretta-Stutenberg \& Morgan-Short, 2017) as well no effects on grammatical development during SA (e.g., Isabelli-García, 2010).

When it comes to speaking proficiency, Di Silvo, Donovan, and Malone (2015, p. 77) noted that numerous studies have also compared oral proficiency outcomes of students studying abroad with control groups at their home universities and found that groups abroad are more likely to make greater gains than those studying at home (Freed, 1995; Segalowitz \& Freed, 2004; Vande Berg et al., 2009). At the same time, we have to highlight the fact that findings from studies using the Language Contact Profile (LCP) have not been consistent in supporting the common assumption that increased contact leads to greater improvement in speaking performance (Di Silvo, Donovan \& Malone, 2015, p. 77). However, what might play a role when it comes to language gains and social network development is the quality and not the quantity of the interactions. This was reflected in the study by Baker-Smemoe et al. (2014) where no significant differences in the amount of the L2 use between high and no language gainers were reported but the differences were in the type of a social network developed by the informants of their study. Consequently, those students who were able to establish a close relationship with target language speakers were reported to be high language gainers. A study by Dewey, Belnap, and Hilstrom (2013) investigated the relationship between social network development and perceived gains in oral proficiency by learners of Arabic in a semester program. Predictors of gains included greater intensity of friendships, more time spent speaking with people outside of established social circles, and higher levels of English language proficiency of Arab friends. Another study that showed that establishing a close relationship with the target language speakers might lead to substantial linguistic gains was the one by Dewey (2008). He found that vocabulary development by learners of Japanese in semester study abroad program was more highly correlated with time spent speaking with friends than speaking with host families which could suggest that interactions in the target language with significant others might influence target language proficiency development. Therefore, it could be speculated that high-quality interaction in the target language leading to establishing bonds might trigger L2 oral proficiency and consequently result in higher L2 speaking gains.

The overview of the literature presented above showed that various psychological (personality traits), and socio-psychological factors (attitudes, motivation) are often intertwined in influencing different aspects of the SA program, such as the development of the target language proficiency, cultural adaptation 
and satisfaction with the SA experience. At the same time, with reported considerable variability in learning outcomes among SA students, it is still not clear what factors may trigger L2 proficiency while abroad. Therefore, the current study was designed to assess the possible role of different psychological and socio-psychological variables in the development of the target language proficiency in different contexts of the L2 use (immersive and nonimmersive).

\section{Method}

\section{Research Questions}

The present study is to address the following research questions:

1. Is there any difference in self-perceived L2 proficiency development between students doing their practicum abroad and those doing it at the local schools in the country of their residence?

2. Is there any difference in L2 grammar and speaking proficiency development between students doing their practicum abroad and those doing it at the local schools in the country of their residence?

3. Is there any link between personality traits, language engagement and attitudes/satisfaction and L2 grammar and oral proficiency development?

\section{Participants}

The participants of this study were 11 Spanish/Catalan learners of English as their L2. They were all 21-year-old females and majored their fourth year of an Education degree at a private university in Barcelona. The informants of the study self-selected themselves to undertake their three-month language teaching practicum abroad, as a part of the Erasmus + mobility program $(n=6)$, or at local schools in Barcelona $(n=5)$. Among the Erasmus+ mobility recipients, four went to London and two to Finland.

\section{Instruments}

In the present study, a battery of tests was applied. Two of them measured personality traits (Big Five Personality Questionnaire; Multicultural Personality Questionnaire). One measured emotional intelligence (Trait Emotional Intell- 
igence Questionnaire) and four other tests were used to measure English (L2) proficiency (Oxford Placement Test; Self-reported Proficiency Questionnaire; Speaking test based on the Cambridge Advanced Exam) as well as frequency of the L1 and L2 use (Language Engagement Questionnaire). Below we provide a detailed description of all enumerated questionnaires.

The Big-Five Personality Test. The Big-Five broad domains personality test (Goldberg, 1992), obtained from the International Personality Item Pool (IPIP), measured personality traits such as Extraversion, Agreeableness, Conscientiousness, Emotional Stability/Neuroticism, and Openness. Subjects responded to each item on a five-point Likert scale. The scale indicating; "never or almost never true of me," "usually not true of me," "somewhat true of me," "usually true of me," "always or almost always true of me." These categories were assigned values of 1, 2, 3, 4, and 5 respectively. The correlation of the IPIP Big-Five broad domains Personality Test with the Costa and McCrae (1992) Big-Five factor structure ranged from .66 to .90 with an overall correlation reported as .81 (Goldberg, 1992). The Cronbach's $\alpha$ for the Big-Five broad domains personality test was .84 .

Multicultural Personality Questionnaire. The Multicultural Personality Questionnaire (MPQ) by Van Der Zee and Van Oudenhoven (2000) is a personality assessment questionnaire that was constructed specifically to describe behavior when one is interacting with people from different cultures. The MPQ consisted of 40 Likert type items measuring such factors as cultural empathy, flexibility, social initiative, emotional sociability, and openmindedness. The Cronbach's $\alpha$ for the Multicultural Personality Questionnaire was .86 .

Trait Emotional Intelligence Questionnaire (TEIQue). Petrides and Furnham's (2003) TEIQue used in the present study comprised 30 items rated on seven-point Likert scale providing scores on four factors of broad relevance: Wellbeing, Self-control, Emotionality, and Sociability. TEIQue required participants to use the rating scale from "completely disagree" to "completely agree" with a mid-point of "neither agree nor disagree." The TEIQue Cronbach's $\alpha$ for the whole questionnaire was .88 .

Language Engagement Questionnaire. The Language Engagement Questionnaire (LEQ) by McManus et al. (2014) was used to document participants' language engagement (L1, L2) for a range of different activities. Participants begin by indicating which languages they use on a regular basis (English, French, Spanish, other). For each language selected, participants are provided with a list of 26 activities and are asked to indicate how often they do each 
activity in that language on a 5-point scale, which gives a maximum score of 130 points, choosing from: every day, several times a week, a few times a week, rarely, never. Even though the questionnaire was originally designed for the SA students we have decided to introduce it also to the at-home group to be able to trace potential similarities/differences in L1/L2 use among those at-home students who undertook their practicum in bilingual schools in Barcelona and the stay abroad group.

Oxford Placement Test. An adapted version of the Oxford Placement Test was administered twice to the participants, the first time prior to their departure and the second time after finishing their practicum. The test was completed online and it contained 100 questions addressing English grammar and vocabulary. Each correct answer was attributed two points, which gives a maximum score of 200 points. Immediately after the test, participants were given their score, feedback, and an explanation of their approximate level according to the Common European Framework of Reference for Languages (CEFRL).

Self-reported Proficiency Questionnaire. The Self-reported Proficiency Questionnaire was introduced in order to gather data concerning participants' opinions regarding their overall L2 proficiency as well as L2 proficiency in four micro skills of speaking, writing, listening, and reading. It comprised 5 Likert type items: How would you rate your overall proficiency in English? How would you rate your L2 speaking proficiency? How would you rate your L2 writing proficiency? How would you rate your L2 listening proficiency? How would you rate your L2 reading proficiency?

Speaking test based on Cambridge Advanced Exam. The speaking test followed the guidelines of part 2 of a Cambridge advanced speaking exam (CAE). Participants were given a set of three pictures and were instructed to select and talk about two of the three pictures individually for one minute. Testing took place in a quiet room and participant's individual output was recorded so it could further be analyzed. Three Cambridge-trained evaluators rated learners' speaking abilities on the basis of five different skills: pronunciation, vocabulary, accuracy, communication, and fluency assigning 10 points to each skill (maximum score for the proficiency test was 50 points). A 4-pointscale rubric was used for evaluation and a reliability analysis using an intra-class correlation coefficient (ICC) with a level of "absolute agreement" was conducted on the rating scores. The Cronbach's $\alpha$ reliability coefficient for each speaking skill ranged from .84 to .87 , indicating strong inter-rater reliability. 


\section{Procedure}

All participants were tested in a private university in Barcelona before and after (T1 and T2) their three-month teaching placement. Moreover, all participants also completed a "during practicum" questionnaire addressing their L1 and L2 language usage. T1 and T2 involved a battery of tests, namely the Big Five Personality Questionnaire; the Multicultural Personality Questionnaire, the Trait Emotional Intelligence Questionnaire, the Oxford Placement Test; Selfreported Proficiency Questionnaire and a Speaking test based on the Cambridge Advanced Exam. More details on each instrument can be seen in section 2.2. The tests were administered online in a computer room and students were called out individually into a separate quiet room to perform the speaking test. After completion of the study, participants were given course credit.

\section{Data Analysis}

The first research question concerned possible difference in self-perceived L2 proficiency development between students undertaking their practicum abroad and those undertaking it at local schools in the country of their residence. In order to be able to answer this question we have calculated mean scores for each language skill measured before and after the practicum. Detailed results are presented in Table 1.

Table 1.

Self-perceived L2 proficiency-at-home vs. stay abroad group

\begin{tabular}{|l|c|c|c|c|}
\hline \multicolumn{1}{|c|}{ L2 proficiency } & At-home T1 & At-home T2 & Stay abroad T1 & Stay abroad T2 \\
\hline Overall L2 proficiency & 3.80 & 3.80 & 3.80 & 3.80 \\
\hline L2 speaking proficiency & 4.00 & 4.00 & 4.00 & 4.00 \\
\hline L2 writing proficiency & 4.00 & 4.00 & 4.00 & 3.70 \\
\hline L2 reading proficiency & 4.20 & 4.40 & 3.80 & 3.80 \\
\hline L2 listening proficiency & 4.40 & 4.60 & 3.70 & 4.00 \\
\hline Mean (L2 skills) & 4.15 & 4.25 & 3.87 & 3.87 \\
\hline
\end{tabular}

The results presented above show that both groups of students rated their overall L2 proficiency identically both prior and after the practicum. The reported score was 3.8 on a five-point Likert scale which means that in the majority of cases they perceived themselves as upper-intermediate/advanced users of L2 English. What was interesting to note was the fact that in both groups this rating 
did not change after the practicum. Consequently, it could be speculated that from the SA students' perspective, their stay abroad experience had no influence on their self-perceived L2 proficiency ratings. What is more, after calculating mean scores for all the L2 skills, we could note that the at-home group ranked their L2 proficiency, in all four mentioned skills, higher than the stay abroad group both before and after their practicum. Additionally, even though their overall L2 proficiency score did not change after the practicum, the mean score from all the L2 skills was higher than that reported overall. Regarding the stay abroad group, the mean score was only slightly higher (3.87) and did not change after the practicum. From the results, it is observed that in selfperceived L2 proficiency, both groups reported the same score before and after their three-month practicum at schools. However, the home-stay group ranked their proficiency in all four L2 skills slightly higher than the stay abroad group. This was also reflected in their post-practicum scores, whereas the scores of the stay abroad group remained identical after their SA experience.

The second research question concerned possible differences in L2 grammar and speaking proficiency development among students undertaking their practicum abroad and those undertaking it at the local schools in Barcelona. Detailed results of the analyses are presented in Table 2 and Table 3.

Table 2.

L2 grammar development-at-home vs. stay abroad group

\begin{tabular}{|c|c|c|c|c|}
\hline L2 proficiency & At-home T1 & At-home T2 & Stay abroad T1 & Stay abroad T2 \\
\hline Grammar test score & 142.4 & 144.2 & 142.0 & 161.0 \\
\hline
\end{tabular}

As can be observed in Table 2, the initial grammar test scores in both groups were almost identical. The mean score in the home stay group was 142.4 out of 200 and in the stay abroad group, 142. However, after the practicum, the stay broad group scored higher than the at-home group, receiving a mean score of 161. In regards to the comparison of scores, it may be noted that the at-home group made almost no progress. The difference in the mean scores between $\mathrm{T} 1$ and $\mathrm{T} 2$ was 2.2 , whereas the stay abroad participants progressed substantially with 19 points difference in the mean scores.

As for L2 speaking development, the results presented in Table 3 clearly show that both groups received similar scores during the first data collection phase, just before the beginning of their practicum. However, after the practicum, the at-home group received lower scores (the difference in scores was 3.5 points) and the stay abroad group scored higher (the difference in scores was 5 points). Further analyses showed that the at-home group scored the same or lower in the measured aspects, whereas the stay abroad group got better scores in accuracy, vocabulary, fluency, and pronunciation. Interestingly, the 
greatest progress in L2 speaking development among sojourners was noted in accuracy (2.9 points difference).

Table 3.

L2 speaking development-at-home vs. stay abroad group

\begin{tabular}{|l|c|c|c|c|}
\hline \multicolumn{1}{|c|}{ L2 proficiency } & At-home T1 & At-home T2 & Stay abroad T1 & Stay abroad T2 \\
\hline Overall L2 speaking score & 36.0 & 32.5 & 36.4 & 41.4 \\
\hline Accuracy & 7.0 & 5.5 & 6.6 & 9.5 \\
\hline Vocabulary & 7.0 & 5.5 & 6.6 & 7.9 \\
\hline Communication & 8.0 & 7.5 & 8.3 & 8.3 \\
\hline Fluency & 8.5 & 8.5 & 8.7 & 9.1 \\
\hline Pronunciation & 5.5 & 5.5 & 6.2 & 6.6 \\
\hline
\end{tabular}

The third research question concerned the possible influence of personality traits, language engagement, attitudes and satisfaction on L2 grammar and oral proficiency development. In order to answer this question, an analysis of the individual responses of all participants will be presented by focusing on high- and low-gainers in both groups under question. Importantly, there was only one student that failed to progress in the stay abroad group, and one that made some progress only as far as grammar is concerned. Thus, they were both assigned to the low-gainers category. All remaining students made some substantial progress in both L2 grammar and speaking. On the other hand, in the at-home group, there were no high-gainers that could be included in the analysis. The highest gain among participants of this group was 4 points in the grammar test and no gain in the speaking test was observed. Consequently, analysis of the stay abroad sample focused on both high and low-gainers, whereas the analysis of the at-home sample focused solely on low-gainers. Detailed results of the analyses are presented below in Tables 4, 5, 6, and 7 .

Table 4.

High and low-gainers in the stay abroad group-test scores

\begin{tabular}{|l|c|c|c|c|c|}
\hline Type of learner & $\begin{array}{c}\text { Grammar test } \\
\text { score } \\
\text { (T1 \& T2) }\end{array}$ & $\begin{array}{c}\text { CEFRL level } \\
\text { (T1 \& T2) }\end{array}$ & $\begin{array}{c}\text { Difference in } \\
\text { points }\end{array}$ & $\begin{array}{c}\text { Speaking test } \\
\text { (T1 \& T2) }\end{array}$ & $\begin{array}{c}\text { Difference in } \\
\text { points }\end{array}$ \\
\hline High-gainer 1 & $156 \& 196$ & C1 \& C2 & 40 & $47.5 \& 50$ & 2.5 \\
\hline High-gainer 2 & $112 \& 146$ & B1 \& B2 & 34 & $30 \& 35$ & 5 \\
\hline Low-gainer 1 & $158 \& 150$ & C1 \& C1 & -8 & $30 \& 22.5$ & -7.5 \\
\hline Low-gainer 2 & $138 \& 148$ & B1 \& C1 & 11 & $22.5 \& 22.5$ & 0 \\
\hline
\end{tabular}


As can be noted from Table 4, there is no clear pattern in the level of proficiency among high and low-gainers in the stay abroad group. It can be seen that there is a student (high-gainer 1) whose L2 proficiency at onset is already high (C1), and still shows, despite the ceiling effect, the greatest progress among all participants. Even though her progress in the speaking test is not remarkable, she achieved the highest of all scores at T2. On the other hand, the second high-gainer's level of L2 proficiency was initially quite low (B1) but she managed to improve greatly in both L2 grammar and speaking. At the same time, among the low-gainers, there is a student whose initial L2 proficiency is quite high $(\mathrm{Cl})$ but fails to progress while abroad. The second low-gainer managed to improve slightly in grammar test but no such improvement was observed during the speaking test. Since these results are inconclusive, other aspects that could have an impact on L2 proficiency development while abroad were analyzed. Results of these analyses are presented in Table 5.

Table 5.

High and low-gainers in the stay abroad group-students profiles

\begin{tabular}{|l|c|c|c|c|c|c|}
\hline Type of learner & $\begin{array}{c}\text { Cultural } \\
\text { empathy }\end{array}$ & $\begin{array}{c}\text { Open- } \\
\text { midedness }\end{array}$ & $\begin{array}{c}\text { Emotional } \\
\text { Intelligence }\end{array}$ & $\begin{array}{c}\text { L1 } \\
\text { engagement }\end{array}$ & $\begin{array}{c}\text { L2 } \\
\text { engagement }\end{array}$ & $\begin{array}{c}\text { Attitudes and } \\
\text { satisfaction }\end{array}$ \\
\hline Max score & 40 & 40 & 210 & 130 & 130 & 5 \\
\hline High-gainer 1 & 39 & 39 & 191 & 83 & 103 & 5 \\
\hline High-gainer 2 & 39 & 38 & 188 & 100 & 112 & 5 \\
\hline Low-gainer 1 & 35 & 37 & 168 & 105 & 68 & 2 \\
\hline Low-gainer 2 & 37 & 33 & 163 & 104 & 98 & 1 \\
\hline
\end{tabular}

From the personality profiles of both high and low-gainers in the study abroad group, it may be noted that the high gainers obtained somewhat higher scores on cultural empathy and open-mindedness variables and significantly higher ones on emotional intelligence. However, what differed in both groups was language engagement, attitudes towards their stay abroad as well as satisfaction towards their teaching practicum. As can be seen in Table 5, high gainers used their L2 to a greater extent in comparison to their L1 and had a positive attitude concerning their stay abroad and teaching practicum. On the contrary, the low-gainers used their L1 more often than their L2 and were not happy with their stay abroad and teaching practicum. After some further analyses and interviews, we found out that both students who were assigned to the low-gainer category lived together and did not socialize much with the target language users. They have also complained about their teaching practicum, suggesting that it did not meet their expectations. When it comes to the high-gainers, they were very happy with their stay abroad experience and reported using their L2 to a large degree, especially while engaging in 
long casual conversations and participating in organised social activities (clubs, sports, etc.).

As already noted, because of the fact that in the at-home group there were no high-gainers, we have decided to focus only on low-gainers. Consequently, Table 6 and Table 7 provide a detailed presentation of the scores as well as personality profiles of the low-gainers in this group.

Table 6 .

Low-gainers in the at-home group-test scores results

\begin{tabular}{|l|c|c|c|c|c|}
\hline Type of learner & $\begin{array}{c}\text { Grammar test } \\
\text { score (1 \& 2) }\end{array}$ & $\begin{array}{c}\text { CEFRL level } \\
(1 \& 2)\end{array}$ & $\begin{array}{c}\text { Difference } \\
\text { in points }\end{array}$ & $\begin{array}{c}\text { Speaking test } \\
(1 \& 2)\end{array}$ & $\begin{array}{c}\text { Difference } \\
\text { in points }\end{array}$ \\
\hline Low-gainer 1 & $122 \& 122$ & B1 \& B1 & 0 & $30 \& 22.5$ & -7.5 \\
\hline Low-gainer 2 & $134 \& 136$ & B2 \& B2 & 2 & $35 \& 27.5$ & -7.5 \\
\hline
\end{tabular}

As may be noted, the at-home low-gainers had lower L2 proficiency levels in comparison to the low-gainers and high-gainers in the stay abroad group. At the same time, at-home students failed to make any progress or made a little progress in L2 grammar and regressed significantly on the L2 speaking test. While analyzing their personality profiles (Table 7), it can be observed that they obtained lower scores on cultural empathy and open-mindedness in comparison to participants in the stay abroad group. Moreover, their scores on emotional intelligence did not differ dramatically from the low-gainers in the stay abroad group. Another variable that was quite similar in both low-scorers' groups was language engagement. In all reported cases, low-scorers' L1 was used more frequently than the L2. However, in the stay abroad group, selfreported frequency of the L2 use was much higher. Interestingly, none of the low-gainers in either group reported engaging in long casual conversations or participating in organised social activities as did the high-gainers. On contrary, they have mentioned receptive skills, such as watching TV and/or listening to music.

Table 7.

Low-gainers in the at-home group-students profiles

\begin{tabular}{|l|c|c|c|c|c|c|}
\hline $\begin{array}{c}\text { Type } \\
\text { of learner }\end{array}$ & $\begin{array}{c}\text { Cultural } \\
\text { empathy }\end{array}$ & $\begin{array}{c}\text { Open- } \\
\text { mindedness }\end{array}$ & $\begin{array}{c}\text { Emotional } \\
\text { Intelligence }\end{array}$ & $\begin{array}{c}\text { L1 } \\
\text { engagement }\end{array}$ & $\begin{array}{c}\text { L2 } \\
\text { engagement }\end{array}$ & $\begin{array}{c}\text { Attitudes and } \\
\text { satisfaction }\end{array}$ \\
\hline Max score & 40 & 40 & 210 & 130 & 130 & 5 \\
\hline Low-gainer 1 & 30 & 31 & 170 & 89 & 55 & 5 \\
\hline Low-gainer 2 & 36 & 30 & 167 & 102 & 45 & 5 \\
\hline
\end{tabular}




\section{Discussion}

The present study addressed three research questions. The first two questions considered possible differences in self-reported overall L2 proficiency, L2 proficiency in all four language skills (speaking, writing, reading, and listening) as well as L2 grammar and speaking test results among stay abroad and at-home students. The results showed that the stay abroad group perceived both their overall L2 proficiency and their L2 proficiency in all mentioned language skills identically prior and after their sojourn. On the contrary, the at-home group reported higher self-perceived L2 proficiency during the second phase of the data collection (i.e., after completing their practicum) but only when it came to separate L2 skills. What is even more surprising is the fact that objective L2 grammar and speaking test results showed something quite contradictory. According to mentioned results, almost all members of the stay abroad group made substantial progress in both L2 grammar and speaking development. Conversely, the at-home students showed some regress in their scores and there were no high-gainers in that group (the only reported gain was 4 points in a grammar test and no gain in the speaking test). It is very difficult to explain these results, however, it could be speculated that the stay abroad group did not report any progress in their self-perceived L2 proficiency after their sojourn due to having faced some difficulties in communication in the foreign language while abroad. The very act of undertaking their practicum at schools where their students were native speakers of English could also be somewhat intimidating at first and consequently influence their self-reports. On the contrary, the at-home group was not confronted with the need to communicate in their L2 on an everyday basis and during their practicum they would most typically teach English to L1 speakers of Spanish and not to students whose L1 is English. These factors might also pertain to the perceptions of higher L2 proficiency development reflected in their self-reports.

The results of our study also showed that the stay abroad group made greater L2 gains than students doing their practicum at home, which is in line with some previous studies (Freed, 1995; Segalowitz \& Freed, 2004; Vande Berg et al., 2009). It could be speculated that the lack of university classes as well as constant contact with learners at low proficiency level might be somewhat detrimental to the participants' proficiency level. At the same time, it is important to note that there are some discrepancies between self-reports and more objective test results.

Addressing the last research question, which concerned a possible link between personality traits, language engagement, attitudes/satisfaction and L2 grammar and oral proficiency development, data analyses showed that the variables that clearly differentiated high-gainers from no-gainers or low-gainers were language engagement factor, satisfaction and attitudes. The participants 
who were assigned to the high-gainers group reported more frequent use of their L2 than their L1 as well as establishing a larger social network that consisted of target language users. They also reported engaging in long casual conversations and participating in organized social activities, which was never the case among low-gainers. We can speculate that negative attitudes and dissatisfaction with the practicum experience influenced their choice in refraining from any extra contact with target language users and communicating mostly in their L1, which was also reflected in their very limited L2 progress. These results are in line with previous studies that showed that students who were able to establish a close relationship with target language speakers were reported to be high language gainers (Baker-Smemoe et al., 2014; Dewey, 2008; Dewey, Belnap, \& Hilstrom, 2013).

In the case of the personality profiles of the high and low-gainers in our study it could be noted that their scores differed minimally in cultural-empathy and open-mindedness but the discrepancies in their scores on emotional intelligence were much larger. At the same time, scores of the low-gainers in the at-home group were much lower than the ones of the low-gainer sojourners. Therefore, it could be speculated that personality might be a mediating variable influencing both cultural adjustment, development of the social network and intensity of the L2 use while abroad. Some previous studies (Arvidsson et al., 2018; Basow \& Gaugler, 2017; Harrison \& Voelker, 2008; Ożańska-Ponikwia, 2015; Ożańska-Ponikwia \& Dewaele, 2012; Savicki et al., 2004) have already shown that personality and emotional intelligence might play a role when it comes to adaptation in the host culture as well as frequency of the L2 use. Consequently, we might speculate that it underpins the frequency of the L2 use while abroad, which leads to establishing larger social networks, higher cultural adaptation and greater satisfaction from the SA experience as well as higher L2 gains.

\section{Limitations of the Study}

This paper reports a small-scale study, and as such, it had its limitations. First of all, only 11 students participated in this first stage of the research, since the group of students available was reduced. Further research should be conducted with a larger number of participants, so that more robust claims can be made. Another limitation is connected with the short amount of time that participants spent abroad (i.e., 3 months). Ideally, longer periods of SA should be investigated. Moreover, while some students sojourned in an English speaking country, others spent their time abroad in Finland, a country where English is widely used, but as a Foreign Language. 


\section{Conclusions}

The present contribution focused on various factors that might contribute to the development of the L2 grammar and speaking proficiency in different context of the L2 use (i.e., immersive and non-immersive setting). While the results of this small scale case study showed that indeed the stay abroad group was the only one that showed improvement in both measured aspects, it also highlighted the fact that some students within that group failed to make any progress. It could be speculated that in the case of the researched informants, their progress in L2 grammar and speaking could be assigned mostly to the amount and quality of the language input outside of the classroom setting. Moreover, some further analyses showed that the relationship between attitude, language engagement, and development of social networks might be of crucial importance, as it influences exposure to the target language and consequently L2 proficiency development while abroad. At the same time, it is important to mention that the personality profiles of the informants might also play an important role. They may act as the variable moderating the whole process and possibly influencing social network development, frequency of the L2 use, cultural adaptation, and satisfaction with the sojourn.

\section{References}

Arvidsson, K., Eyckmans, J., Rosier, A., \& Forsberg Lundell, F. (2018). Self-perceived linguistic progress, target language use and personality development during study abroad. Study Abroad Research in Second Language Acquisition and International Education, 3(1), 144-166.

Baker-Smemoe, W., Dewey, D. P., Bown, J., \& Martinsen, R. A. (2014). Variables affecting L2 gains during study abroad. Foreign Language Annals, 47, 464-486.

Basow, S. A., \& Gaugler, T. (2017). Predicting adjustment of U.S. college students studying abroad: Beyond the multicultural personality. International Journal of Intercultural Relations 56, 39-51.

Bryfonski, L \& Mackey, A. J. (2018). Enteraction in study abroad settings. In C. Sanz \& A. Morales-Front (Eds.), The Routledge Handbook of Study Abroad Research and Practice (pp. 374-384). London: Routledge.

Collentine, J. (2009). Study abroad research: Findings, implications and future directions. In M. H. Long \& C. J. Doughty (Eds.), The handbook of language teaching (pp. 218-233). Oxford: Wiley-Blackwell.

Costa, P. T., \& McCrae, R. R. 1992. Revised NEO Personality Inventory (NEO PI-R) and NEO Five-Factor Inventory (NEO-FFI). Professional manual. Odessa, FL: Psychological Assessment Resources. 
Cubillos, J. H., Chieffo, L., \& Fan, C. (2008). The impact of short-term study abroad programs on L2 listening comprehension skills. Foreign Language Annals, 41, 157-186.

DeKeyser, R. (2010). Monitoring processes in Spanish as a second language during a study abroad program. Foreign Language Annals, 43, 80-92.

Dewaele, J.-M. (2009). Perception, attitude and motivation. In V. Cook \& Li Wei (Eds.), Language teaching and learning (pp. 163-192). London: Continuum.

Dewey D. P. (2008). Japanese vocabulary acquisition by learners in three contexts. Frontiers: The Interdisciplinary Journal of Study Abroad, 15, 127-148.

Dewey, D., Belnap, R., \& Hillstrom, R. (2013). Social network development, language use, and language acquisition during study abroad: Arabic language learners' perspectives. Frontiers: The Interdisciplinary Journal of Study Abroad, 22, 84-110.

Di Silvio, F., Donovan, A., \& Malone, M. E. (2014). The effect of study abroad homestay placements: Participant perspectives and oral proficiency gains. Foreign Language Annals, 47(1).

Faretta-Stutenberg, M., \& Morgan-Short, K. (2017). Contributions of initial proficiency and language use to second-language development during study abroad: Behavioral and eventrelated potential evidence. In C. Sanz \& A. Morales-Font (Eds.), The Routledge Handbook of Study Abroad Research, (pp. 421-436). New York, NY: Routledge.

Freed, B. F. (1995). Language learning and study abroad. In B. Freed (Ed.), Second Language Acquisition in a Study Abroad Context (pp. 3-33). Philadelphia: John Benjamins.

Freed, B., Segalowitz, N., \& Dewey, D. (2004). Context of learning and second language fluency in French: Comparing regular classroom, study abroad, and domestic immersion programs. Studies in Second Language Acquisition, 26(2), 275-301.

Gabel, R. S., Dolan, S. L., \& Cerdin, J. L. (2005). Emotional intelligence as predictor of cultural adjustment for success in global assignments. Career Development International, 10(5), 375-395.

Gardner, R. (2012). Integrative motivation and global language (English) acquisition in Poland. Studies in Second Language Learning and Teaching, 2(2), 215-226.

Gardner, R., \& Lalonde, R. (1985). Second Language Acquisition: A Social Psychological Perspective. Paper presented at the Annual Convention of the American Psychological Association, Los Angeles, August 23-27.

Goldberg, L. R. 1992. The Development of Markers for the Big-Five Factor Structure. Psychological Assessment, 4(1), 26-42.

Grey, S., Cox, J., Serafini, E. J., \& Sanz, C. (2015). The role of individual differences in the study abroad context: Cognitive capacity and language development during short-term intensive language exposure. The Modern Language Journal, 99(1), 137-157.

Harrison, J. K., \& Voelker, E. (2008). Two personality variables and the cross-cultural adjustment of study abroad students. Frontiers: The Interdisciplinary Journal of Study Abroad, $17,69-87$.

Hessel, G. (2017). A new take on individual differences in L2 proficiency gain during study abroad. System, 66, 39-55.

Howard, M. (2005). The emergence and use of the 'plus-que-parfait' in advanced French interlanguage. In J.-M. Dewaele (Ed.), Focus on French as a foreign language: Multidisciplinary perspectives (pp. 63-87). Clevedon, England: Multilingual Matters.

Howard, M., \& Schwieter, J. W. (2018). The development of second language grammar in a study abroad context. In C. Sanz \& A. Morales-Front (Eds.), The Routledge handbook of study abroad research and practice (pp. 135-148). New York, NY: Routledge.

Huang, T.-J., Chi, S.-C., \& Lawler, J. J. (2005). The relationship between expatriates' personality traits and their adjustment to international assignments. International Journal of Human Research Management, 16, 1656-1670. 
Isabelli-Garcia, C. (2006). Study abroad social networks, motivation, and attitudes: Implications for second language acquisition. In M. Dufon \& E. Churchill (Eds.), Language learners in study abroad contexts 231-258. Clevedon, England: Multilingual Matters.

Isabelli-García, C. (2010). Acquisition of Spanish gender agreement in two learning contexts: Study abroad and at home. Foreign Language Annals, 43(2), 289-303.

Jassawalla, A., Truglia, C., \& Garvey, J. (2004). Cross-cultural conflict and expatriate manager adjustment: An exploratory study. Management Decision, 42(7), 837-849.

Kinginger, C. (2004). 'Alice doesn't live here anymore': Foreign language learning and renegotiated identity. In A. Pavlenko \& A. Blackledge (Eds.), Negotiation of Identities in Multilingual Contexts (pp. 219-242). Clevedon, England: Multilingual Matters.

Kinginger, C. (2008). Language learning in study abroad: Case studies of Americans in France. Malden, MA, \& Oxford, UK: Wiley-Blackwell.

Kinginger, C. (2009). Language learning and study abroad: A critical reading of research. Basingstoke: Palgrave Macmillan.

Kinginger, C. (2015). Language socialization in the homestay: American high school students in China. In R. Mitchell, N. Tracy-Ventura, \& K. McManus (Eds.), Social interaction, identity and language learning during residence abroad. EUROSLA Monographs 4, 53-74. Amsterdam: European Second Language Association.

Marijuan, S., \& Sanz, C. (2018). Expanding Boundaries: Current and New Directions in Study Abroad Research and Practice. Foreign Language Annals, 51, 185-204.

McManus K., Mitchell, R., \& Tracy-Ventura, N. (2014). Understanding insertion and integration in a study abroad context: The case of English-speaking sojourners in France. Revue française de linguistique appliquée, 19, 97-116.

Mitchell, R., Tracy-Ventura, N., \& McManus, K. (2017). Anglophone students abroad: Identity, social relationships and language learning. In Anglophone Students Abroad: Identitv Social Relationships, and Language Learning (pp. 1-266). Taylor and Francis. doi: org/10.4324/9781315194851

Mougeon, R., Rehner, K., \& Nadasdi, T. (2004). The learning of spoken French variation by immersion students from Toronto Canada. Journal of Sociolinguistics, 8, 408-432.

Nadasdi, T., Mougeon, R., \& Rehner, K. (2003). Emploi du 'futur' dans le français parlé des élèves d'immersion française. Journal of French Language Studies, 13, 195-219.

Ożańska-Ponikwia, K. (2013). Emotions from a bilingual point of view. Personality and emotional intelligence in relation to perception and expression of emotions in the L1 and L2. Newcastle: Cambridge Scholars Publishing.

Ożańska-Ponikwia, K. (2015). Cross-cultural communication and bilingualism: The influence of immersion in the L2 culture on self-perceived L2 proficiency and L2 use. In K. OżańskaPonikwia \& B. Loranc-Paszylk (Eds.), Cross-cultural perspectives on bilingualism and bilingual education (pp. 11-38). Bielsko-Biała: Wydawnictwo Naukowe Akademii Techniczno-Humanistycznej w Bielsku-Białej.

Ożańska-Ponikwia, K., \& Dewaele, J. M. (2012). Personality and L2 use: The advantage of being open-minded and self-confident in an immigrant context. EUROSLA Yearbook, 12, 112-134.

Pavlenko, A. (2002). Poststructuralist approaches to the study of social factors in second language learning and use. In V. J. Cook (Ed.), Portraits of the L2 User (pp. 277-302). Clevedon, England: Multilingual Matters.

Pavlenko, A. (2005). Emotions and multilingualism. Cambridge, MA: Cambridge University Press.

Petrides, K. V., \& Furnham, A. (2003). Trait emotional intelligence: Behavioural validation in two studies of emotion recognition and reactivity to mood induction. European Journal of Personality, 17, 39-57. 
Regan, V. (2005). From speech community back to classroom: What variation analysis can tell us about the role of context in the acquisition of French as a foreign language. In J.-M. Dewaele (Ed.), Focus on French as a foreign language: Multidisciplinary approaches (pp. 191-209). Clevedon, England: Multilingual Matters.

Regan, V., Lemée, I., \& Howard, M. (2009). Acquisition of sociolinguistic competence in a study abroad context. Irish Learners of French. Clevedon, England: Multilingual Matters.

Sanz, C. (2014). Contributions of study abroad research to our understanding of SLA processes and outcomes: The SALA Project, an appraisal. In C. Perez-Vidal (Ed.), Language acquisition in study abroad and formal instruction contexts (pp. 1-13). Philadelphia-Amsterdam: John Benjamins.

Savicki, V., Downing-Burnette, R., Heller, L., Binder, F., \& Suntinger, W. (2004). Contrasts, changes, and correlates in actual and potential intercultural adjustment. International Journal of Intercultural Relations, 28, 311-329.

Segalowitz, N., \& Freed, B. F. (2004). Context, contact, and cognition in oral fluency acquisition: Learning Spanish in at home and study abroad contexts. Studies in Second. Language Acquisition, 26, 173-199.

Shabitha, M. P., \& Mekala, S. (2013). The impact of psycholinguistic factors on second language acquisition. The IUP Journal of English Studies, 8(1), 7-14.

Vande Berg, M., Connor-Linton, J., \& Paige, R. M. (2009). The Georgetown Consortium Project: Interventions for Student Learning Abroad. Frontiers: The Interdisciplinary Journal of Study Abroad, 18, 1-75.

Van Der Zee, K. I., \& Van Oudenhoven, J. P. (2000). The Multicultural Personality Questionnaire: A multidimensional instrument of multicultural effectiveness. European Journal of Personality, 14(4), 291-309.

Whitworth, K. (2006). Access to learning during study abroad: The roles of identity and subject positioning. Unpublished doctoral dissertation, The Pennsylvania State University. 